\title{
Study and analysis the effect of variable applied voltage on SCIM performances based on FEA
}

\author{
Waleed Khalid Shakir Al-jubori ${ }^{1}$, Yasir Abdulhafedh Ahmed ${ }^{2}$ \\ ${ }^{1}$ Departement of Electrical Engineering, AL-Furat Al-Awsat Technical University, Technical College of Al-Mussaib \\ ${ }^{2}$ Departement of Electrical Engineering, University of Anbar, Iraq
}

\begin{tabular}{l} 
Article Info \\
\hline Article history: \\
Received Feb 20, 2020 \\
Revised Apr 4, 2020 \\
Accepted Apr 27, 2020 \\
\hline
\end{tabular}

Keywords:

Efficiency.

FEM.

SCIM.

Torque

Voltage variation.

\begin{abstract}
Study and analysis the effect of variable applied voltage on SCIM performances based on FEA is presented. Three phase squirrel cage induction motor SCIM has been investigated and numerically simulated using finite element method (FEM) with the aid of ANSYS software (RMxprt and Maxwell 2D/3D). This research presents study and analysis of the effects of the voltage variation on performance and efficiency of the three-phase induction motor of the squirrel cage type. The Finite Elements Analysis Method FEA is used as one of the best methods for analysis and simulation of electrical motors in addition to the possibility of dealing with nonlinear equations, Since the induction motor is a complex electromagnetic reaction, the researchers used the ANSYS program to represent and analyze the performance of the motor under variable supply voltage. The case studied in this research is three phases, $380 \mathrm{~V}, 50 \mathrm{~Hz}, 2.2 \mathrm{~kW}$, induction motor that widely use in industrial application. The aim of this research is to study the effect of voltage variation on efficiency, current value, power factor and torque of SCIM. The RMxprt software has been used for modeling and simulating the induction motor and calculating the values of phases currents, input and output power in additional of overall efficiency at steady state condition. The next stage of the research is creating Maxwell 2-D design from the base model of RMxprt software, Maxwell 2-D model has the ability to computing the distribution of magnetic field and explaining the performance under steady-state operation. The obtained results show significant reduction of motor performance due to the effect of variation of apply voltage.
\end{abstract}

This is an open access article under the CC BY-SA license.

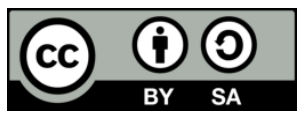

\section{Corresponding Author:}

Waleed Khalid Shakir Al-Jubori

AL-Furat AL-Awsat Technical University, Iraq

Department of Electrical Power Engineering Techniques,

Hillah, Hillah-Najaf street, Babil, Iraq.

Email: waled_k@atu.edu.iq

\section{INTRODUCTION}

Induction motors are spine of industrial, and considers the most widespread and most generally utilized in industrial applications. That is due to its simply design, good efficiency, reliability, low-lying cost and resilience to work in the harsh environment of temperature and stresses. There are two types of three phase induction motor SCIM and slip ring induction motor SRIM, The SCIMs have a widely and increasingly applications in power system field. Due to high power density, efficiency, high power factor and mall size, it becomes a good choice instead of other conventional motors. [1-3]. A study of the basic 
guidelines to develop a coupled FEM for the study of electromagnetic phenomena in I.M presented in [4]. A three phase SCIM is modeled using ANSYS Maxwell software.

A 2D finite element method (FEM) is viewed as a vital apparatus to simulate electrical machines. With and process the attractive motion conveyance. Despite the fact that this technique is tedious and required precise geometric information about machines structure, yet it gives an exact data about the activity $[5,6]$.

Numerical method has been broadly used to comprehend composite domain structure, FEM which is one of these strategies Give an exact calculation for 2D/3D issues of electric machines with complex geometries. This arrangement is utilized to evaluate machine execution a high exactness. Sadly, solving of FEM issues need a total data about the geometry, materials, kind of use to be utilized by electric machine what's more boundary conditions that will be settled. It must be noticed that there are three sorts of FE analysis can be discovered [7, 8]: a) Magneto static analysis. b) Magneto harmonic analysis c) Magneto transient analysis

The steady-state and transient investigation is implemented. The primary sort is known as a magneto static By utilizing the properties of ANSYS Maxwell, RMxprt programming, rated voltage is changed and the performance of the motor are computed. Several factors affect due to voltage variation such as phase current, power factor, output torque and efficiency. In this paper the influence of applied voltage investigated.

\section{MODELING OF SCIM USING FEM}

FEM has been effectively used to get the substantial precise elements and modeling of SCIM and utilized in speed control applications and faults diagnosis systems. This modeling has been vastly used in the domain of electrical machine analysis and design. It has been applied to resolve the Maxwell's equations to search the action of the magnetic field in time and frequency range. In this research, modeling and simulation of SCIM employing FEM coming from through three steps: pre-processing, processing and post-processing [9-11]. Using pre-processing step, the dimension and geometry of the SCIM is realized. The materials feature of stator and rotor cores and shaft are defined. Anyway. Details of the machine dimensions, windings and materials are given in Table1. Finally, in this step the mechanical loads are utilized on the model. A group of Maxwell's equations are resolved in the processing part employing numerical method and after that the magnetic field distribution over the model will be acquired. Stator phase currents and flux density and all other electromagnetic parameters have been acquired and formulated as equilibrium equations. The equations for the entire structure are gained by combining the equilibrium equation of each element such that continuity is ensured at each node [12-14].

The partial differential forms of Maxwell's equations that characterize the quasi stationary fields can be distinct as below $[15,16]$ :

$$
\begin{aligned}
& \nabla \times H=\left(\text { Amper }^{\prime} \text { 'slaw }\right) \\
& \nabla \times E=-\partial B / \partial t(\text { Faraday'slaw }) \\
& \nabla \cdot B=0 \text { (Magneticfluxcontinuity }) \\
& J=\sigma E \\
& B=\mu H
\end{aligned}
$$

The effect of voltages on engine capacity and torque can be illustrated by the following equation assuming $\mathrm{Z} 1=0$ then

$$
T m=\frac{3}{\omega 1} \cdot \frac{V 1^{2} R 2 e}{(R 2 e)^{2}+(S X 2 e)^{2}}
$$

since $T 1=T 2=T$, then

$$
\begin{aligned}
& \frac{V 1^{2} S 1 R 2 e}{(R 2 e)^{2}+(S 1 X 2 e)^{2}}=\frac{V 2^{2} S 2 R 2 e}{(R 2 e)^{2}+(S 2 X 2 e)^{2}} \\
& O R\left(\frac{V 1}{V 2}\right)^{2}=\frac{S 2}{S 1}\left(\frac{R 2 e^{2}+(S 1 X 2 e)^{2}}{R 2 e^{2}+(S 2 X 2 e)^{2}}\right.
\end{aligned}
$$

Since slip variation will not affect the value in the rotor coil of machine then.

$$
\frac{T 1}{T 2}=\left(\frac{V 1}{V 2}\right)^{2}=\frac{S 2}{S 1}
$$

$$
\text { Since } S 1 \times 2 e=S 2 \times 2 e
$$


As appearance from equations above, the applied voltage has a direct effect on motor performances. By using RMxprt, a $2.2 \mathrm{~kW}$ three-phase SCIM is designed. The parameters of the motor are given in Table 1 by inserting the all general information from Table 1 and the type of load applying on the rotor [17- 20].

The B-H curve of laminated steel is defined. The rotor bars are selected as aluminum. The windings are copper. The shaft is assigned as not magnetic steel. The rotor is simulated with all practical dimensions shows in Figure1. The stator and slots information and dimensions that used in simulation are shows in Figure2 including inner and outer diameter in addition of slot dimensional design. [21-23] After interring all information to RMxprt, the user interface of RMxprt is shown in Figure 3.

Table 1. Motor parameters

\begin{tabular}{cc}
\hline Parameter & Unit \\
\hline Stator Outer Diameter & $137.8 \mathrm{~mm}$ \\
Stator Inner Diameter & $78 \mathrm{~mm}$ \\
Stator - Number of Slots & 24 \\
Rotor Outer Diameter & $77.4 \mathrm{~mm}$ \\
Rotor Inner Diameter & $29 \mathrm{~mm}$ \\
Rotor Number of Bars & 20 \\
Stack length & 95 \\
Number of poles & 2 \\
Rated Voltage & 380 \\
Rated Power & $2200 \mathrm{~W}$ \\
Frequency & $50 \mathrm{~Hz}$ \\
Rated Speed & $1850 \mathrm{rpm}$ \\
\hline
\end{tabular}

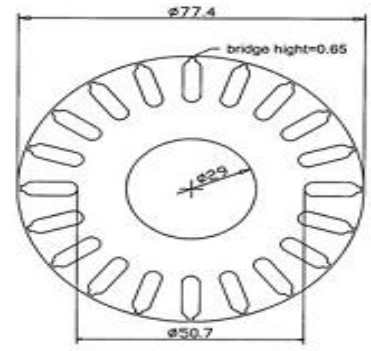

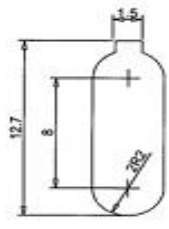

Enlarged view of rotor bar (20 bars)
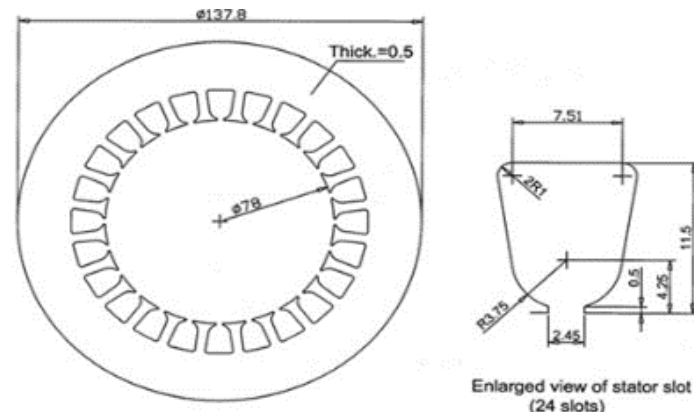

Enlarged view of stator slot

(24 slots)

Figure 1. Rotor dimensions

Figure 2. Stator dimensions

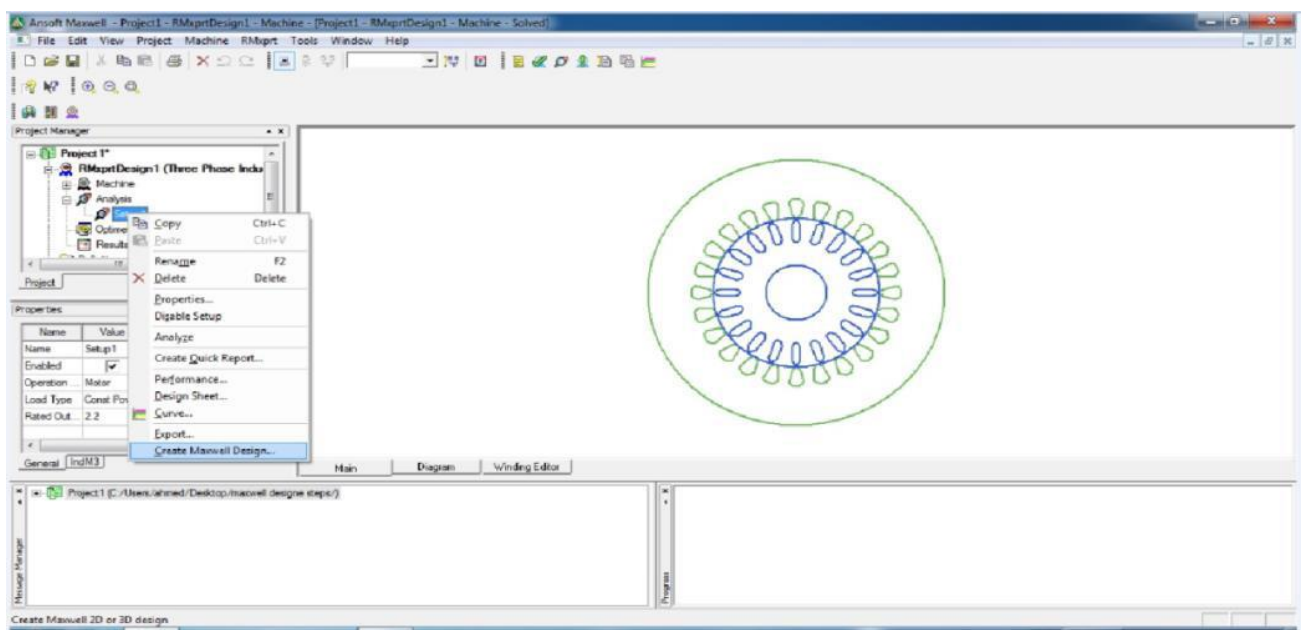

Figure 3. RMxprt user interface 


\section{SIMULATION AND RESULTS}

A 3-phase SCIM which has the parameters given in Table 1 has been modeled and simulated using ANSYS (RMxpert and Maxwell 2D) software. This software provides ability to change the value of applied voltage or any other parameters that may gave an effect on the operation of motor $[24,25]$.

The model of SCIM has been simulated to show the effect of varying the voltage variation in different values. Figure 4 indicate the speed and efficiency with respect to rated voltage of $380 \mathrm{~V}$. Figure 5 shows the variation of efficiency for 340, 420, 460, and 500V. respectively.

As figure 5 the efficiency was decreased when voltage variation up or under $10 \%$. The effect of applied voltage at the power factor are explained in Figure 6.

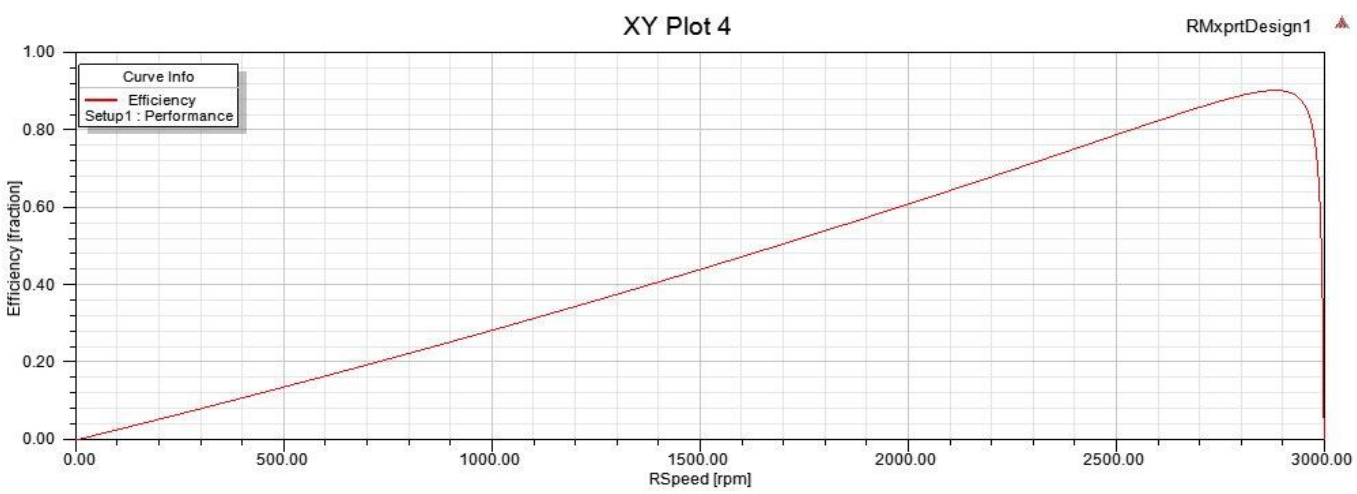

Figure 4. Relationship between Efficiency and Speed at Rated Voltage 380V

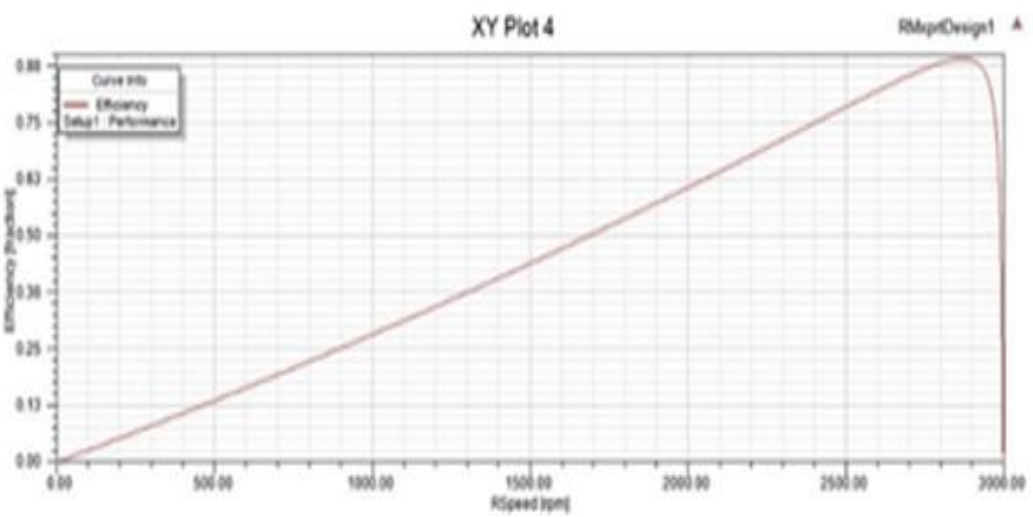

(a)

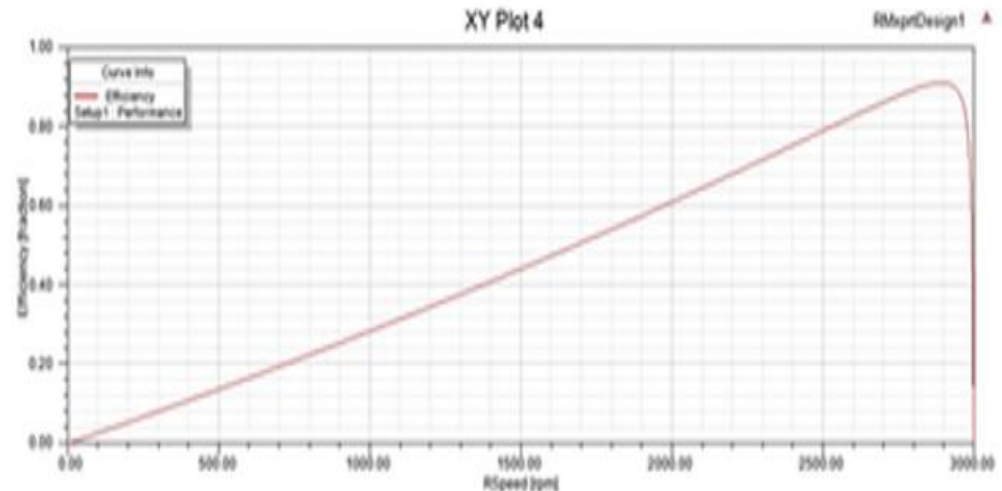

(b) 


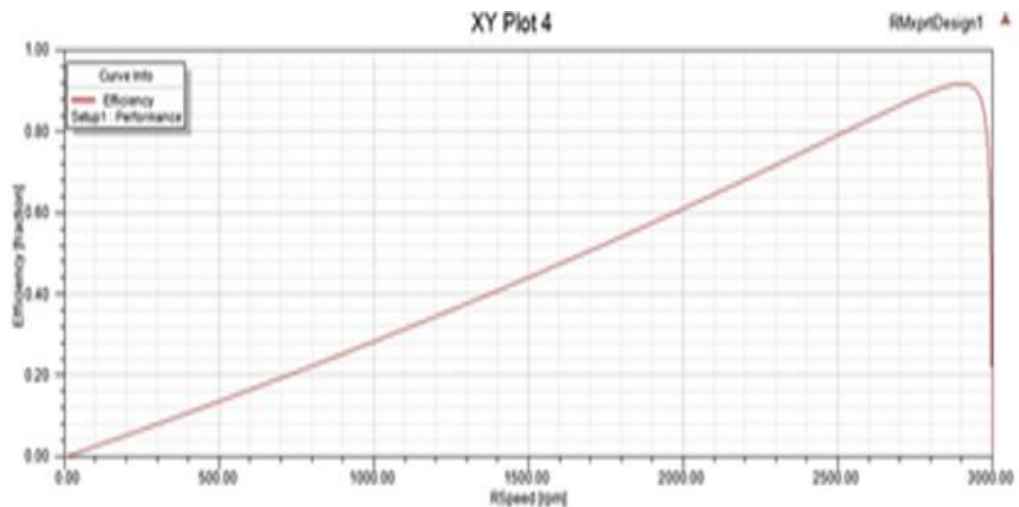

(c)

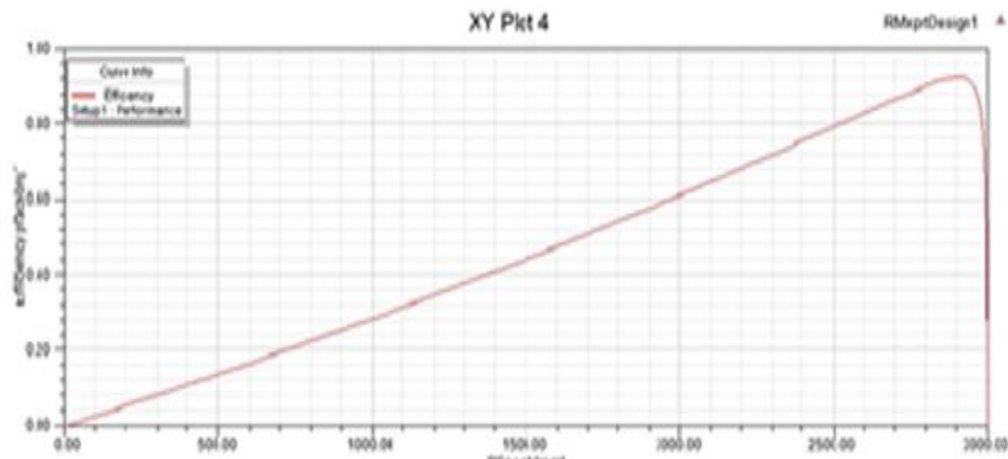

(d)

Figure 5. Relation of Efficiency and Apply Voltage. (a) Efficiency at 340V (b) Efficiency at 420V (c) Efficiency at 460V (d) Efficiency at 500V

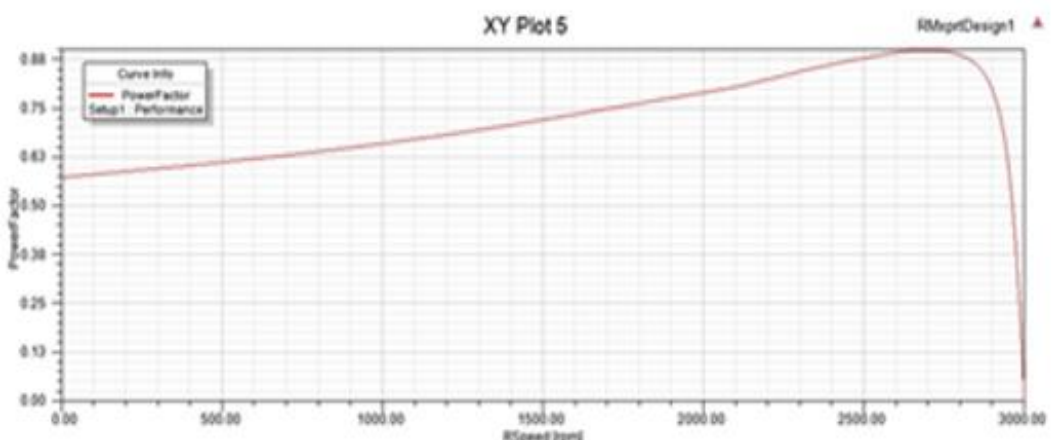

(a)

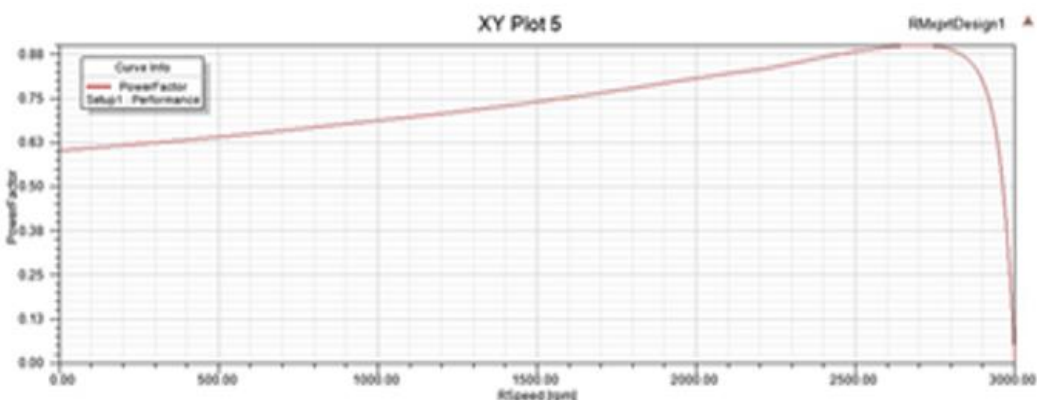

(b) 


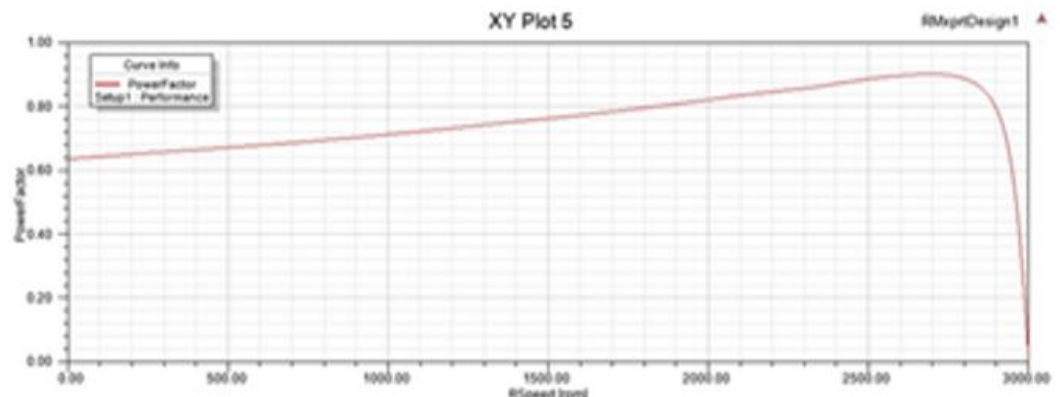

(c)

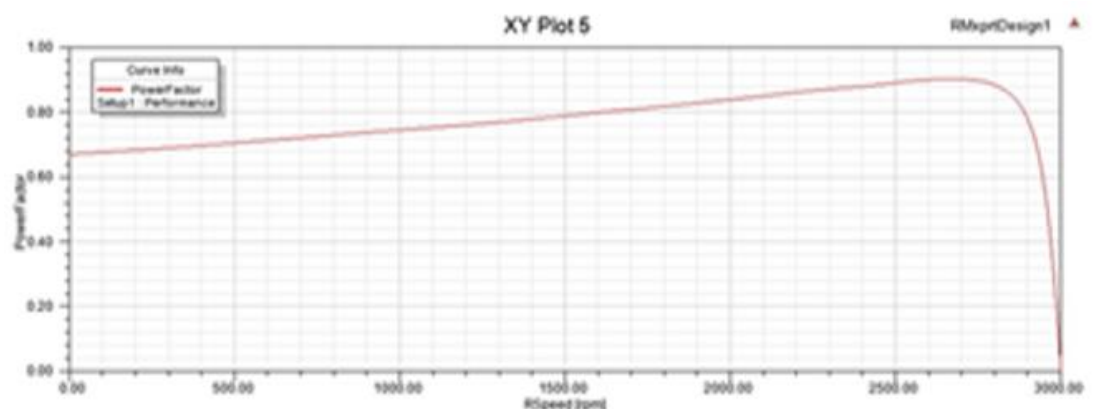

(d)

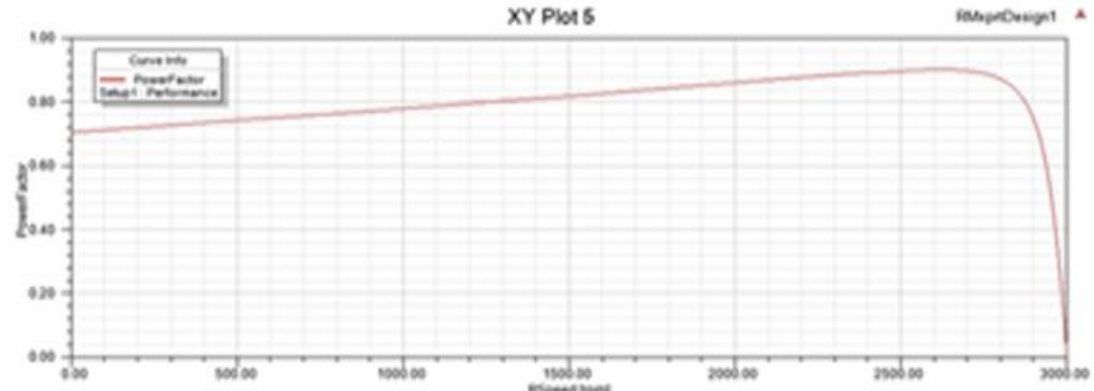

(e)

Figure 6. The Effect of Applied Voltage at The Power Factor (a) P.F At 340V (b) P.F At 380V(c) P,F At 420V (d) P.F At 460V (e) P.F At 500V

That clear from Figure 6 the negative effect of applied voltage on motor power factor. The effect of voltage variation at rated torque is shown in Figure 7. Then the five cases studied of deferent values of applied voltage appear that the large variation in voltage is between 340 to $500 \mathrm{~V}$ and above or over that will be give a distortion in motor performants and large possibility of damage.

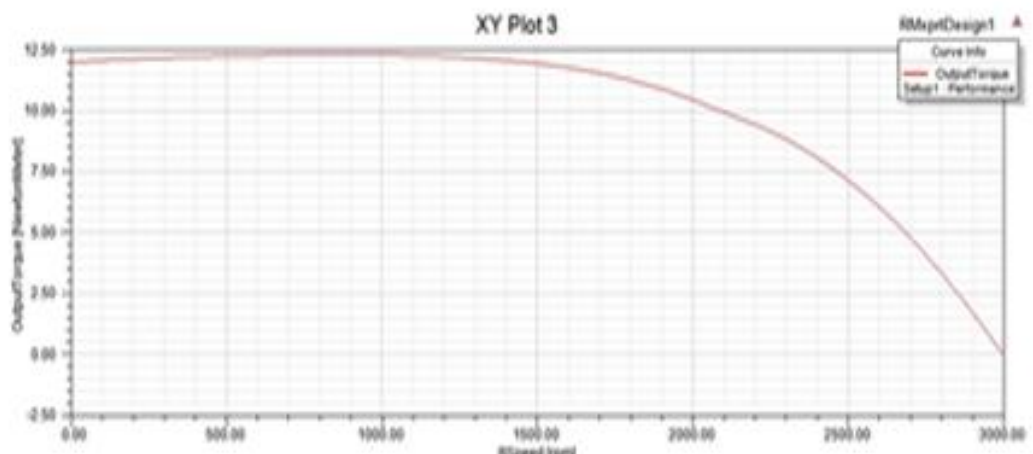

(a) 


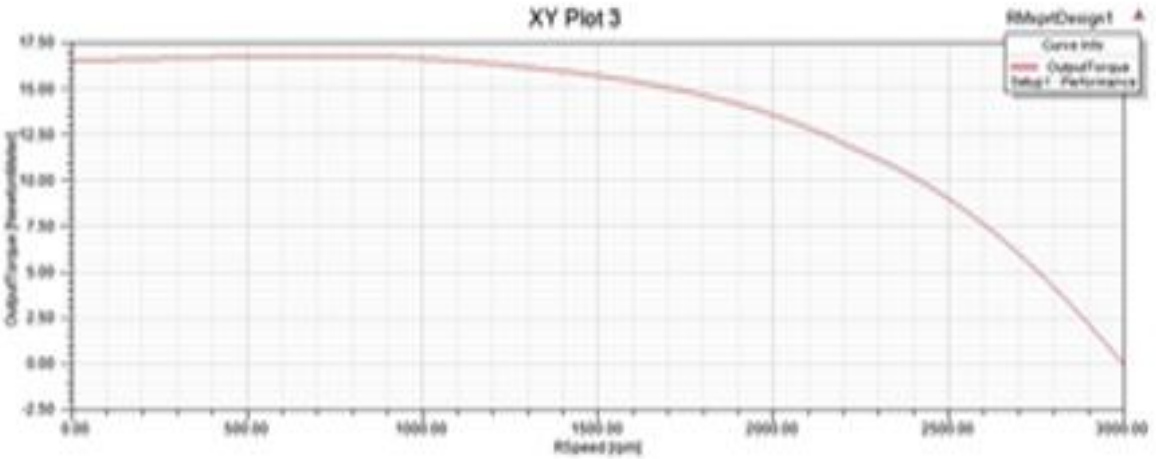

(b)

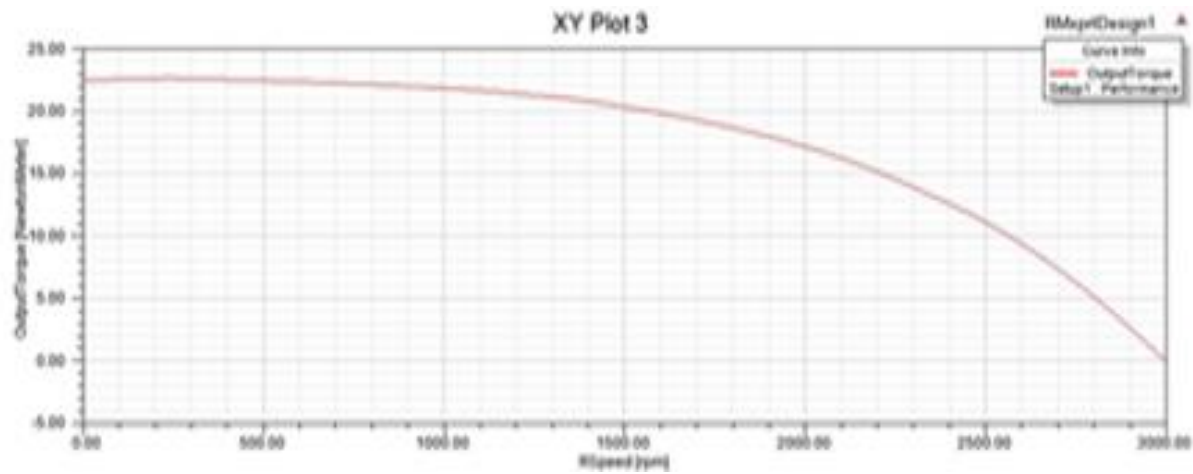

(c)

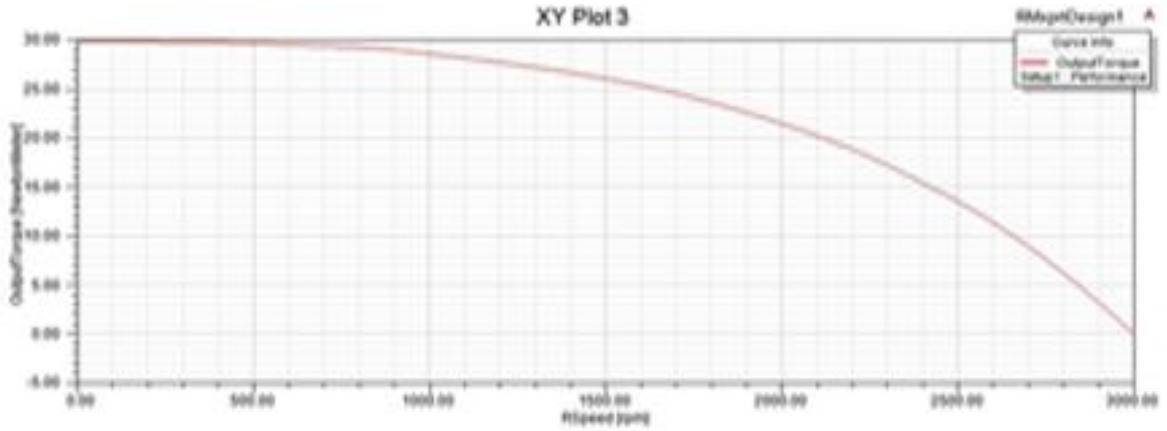

(d)

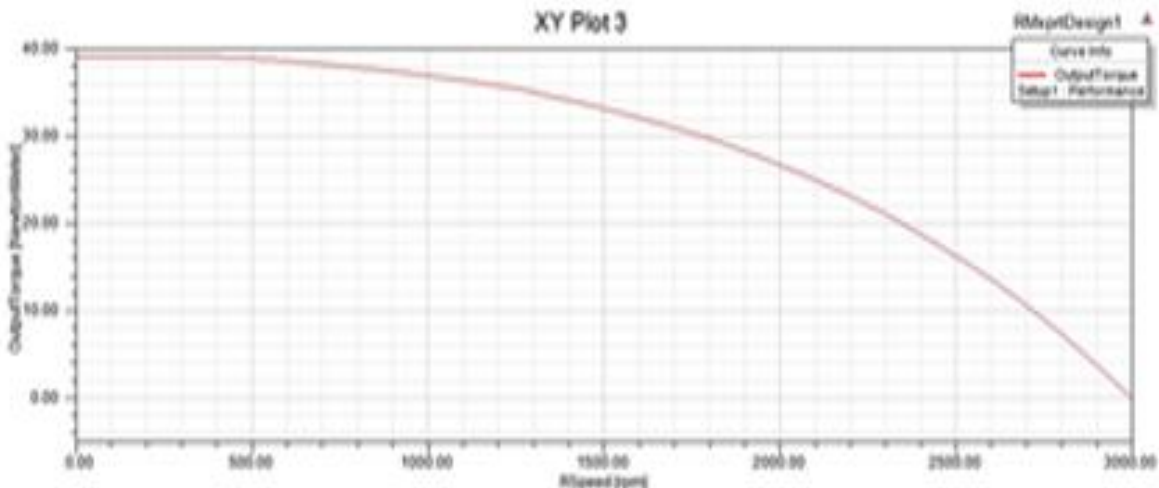

(e)

Figure 7. The Effect of Applied Voltage at The Output Torque (a) Torque at 340V (b) Torque at 380V (c) Torque at $420 \mathrm{~V}$ (d) Torque at $460 \mathrm{~V}$ (e) Torque at $500 \mathrm{~V}$ 


\section{SIMULATION RESULTS OF SCIM USING 2-D FINITE ELEMENT MODEL}

To investigate the time stepping operation of SCIM, a model has been transposed from RMxprt to Maxwell 2-D. A magnetic flux distribution over the model structure is computed using FEM as shown in figure 8 . Then the dynamic performance parameters which include stator currents, back emfs, developed torque, and so on have been accurately. The same design parameters in the suggested three cases that have been analyzed in steady state analysis are used to compute the transient operation of the motor. Figure 8 presents the 2-D modelling of SCIM in FEA and Maxwell2D which solve the Magneto transient analysis of the motor

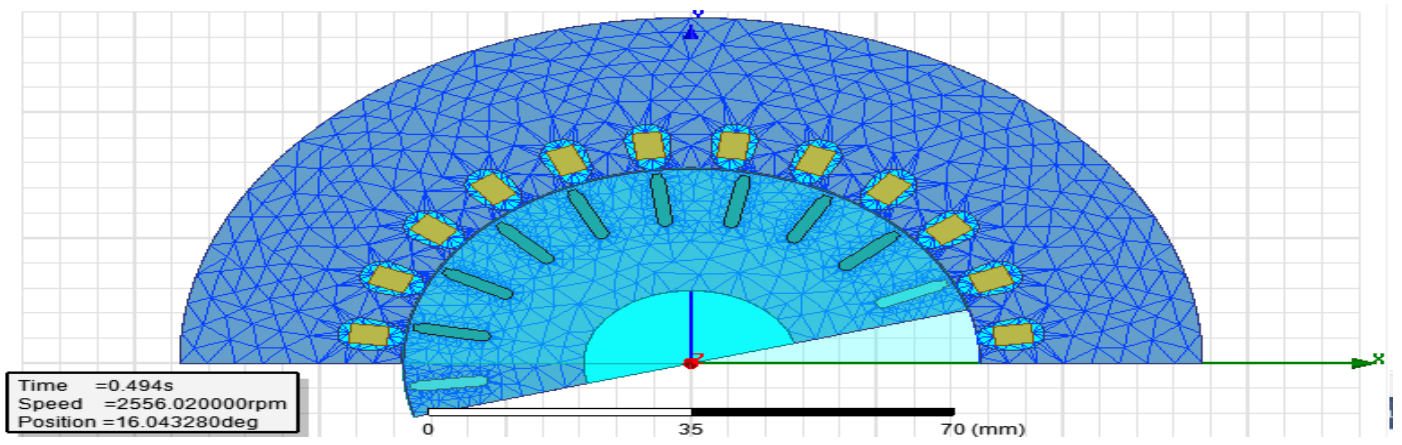

Figure 8. 2-D model of SCIM.

Figures 9, 10 and 11 give the operating torque, stator current and motor total power and show clearly the effect of applied voltages on the motor performances that gives a negative effect when the variation of applied voltages over or under 10\%. Figure 9 shows the torque curves for different voltages.

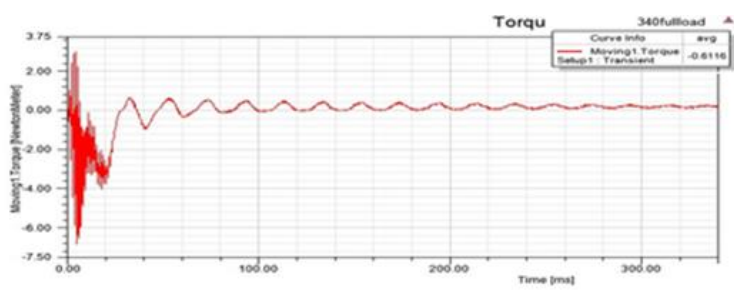

(a)

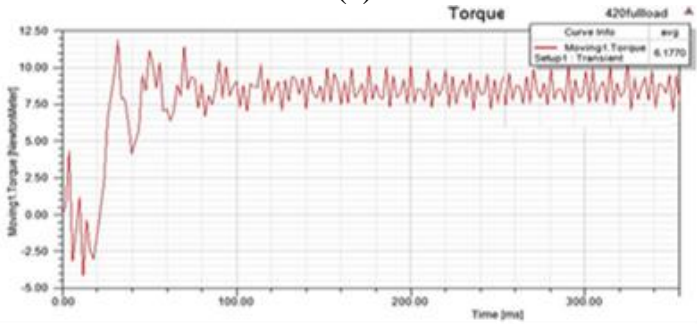

(c)

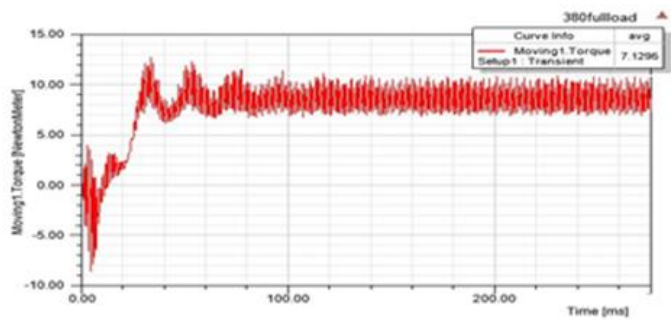

(b)

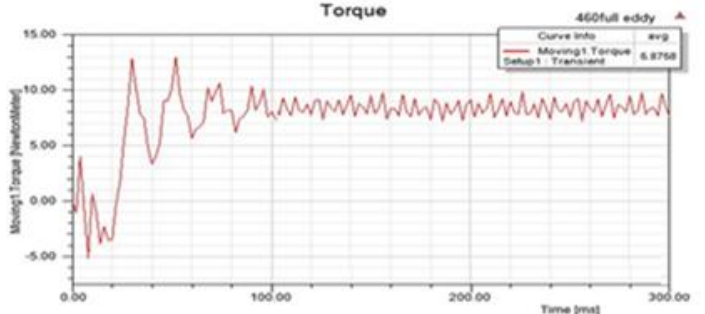

(d)

Figure 9. Torque curves (a) Torque at 340, (b) Torque at 380, (c) Torque at 420V, and Torque at 460V

As appear in Figure 9 a, c and d the torque is decrease when applied voltage is increase or decrease, but the figure a and $\mathrm{c}$ is acceptable values of torque while figure $\mathrm{d}$ is very large deviation in torque.

Figure 10 shows the stator current for different applied voltages and Figure 11 shows the power at different applied voltages. 


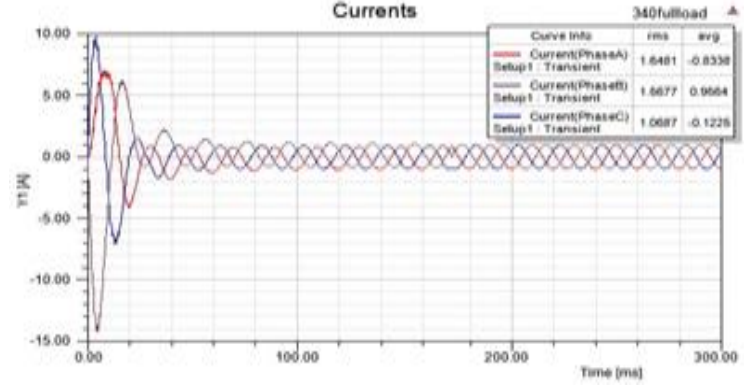

(a)

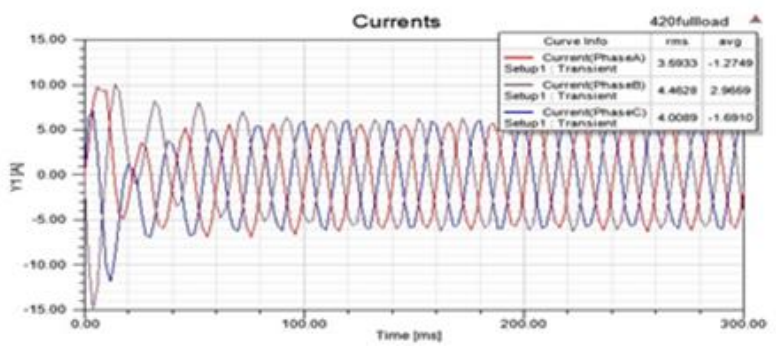

(c)

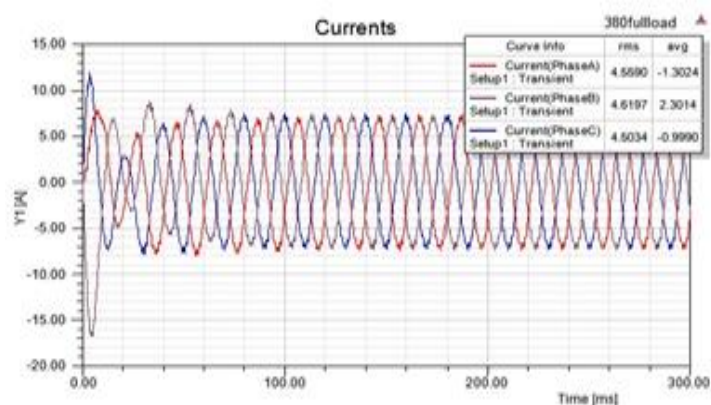

(b)

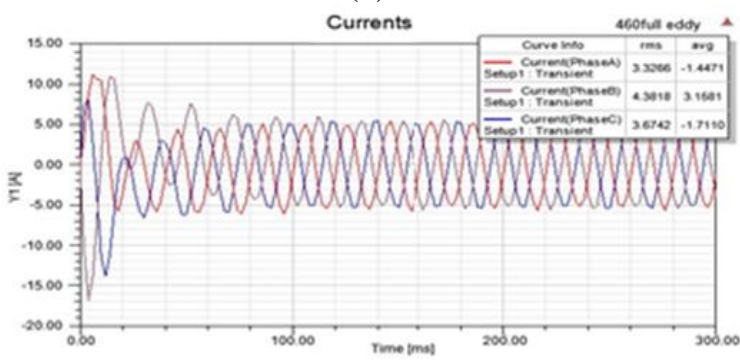

(d)

Figure 10. Stator current waveform at different voltage. (a)Stator Current at 340V (b)Stator Current at 380V (c)Stator Current at 420V (d)Stator Current at 460V

From the results shown in Figures 9,10 the applied voltage variation has negative effects on the motor phase currents and torque is appear that the motor torque is decreased when motor supplying from upper or lower voltage and the torque is decreased when the applied voltage be change more than $\pm 10 \%$. From Figure 11 and the Maxwell 2D analysis the overall efficiency for different values of applied voltage the efficiency was appear as Figure 12.

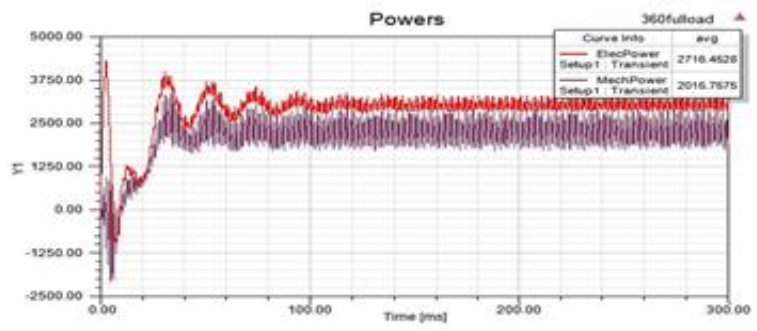

(a)

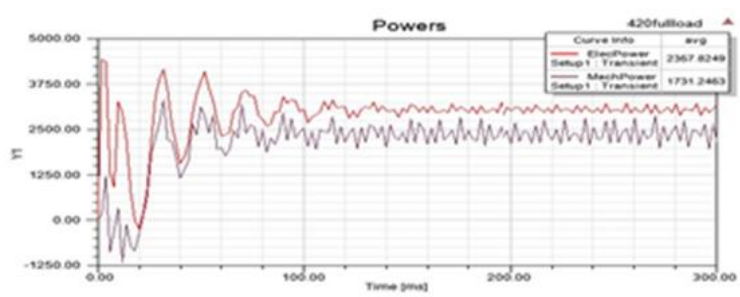

(c)

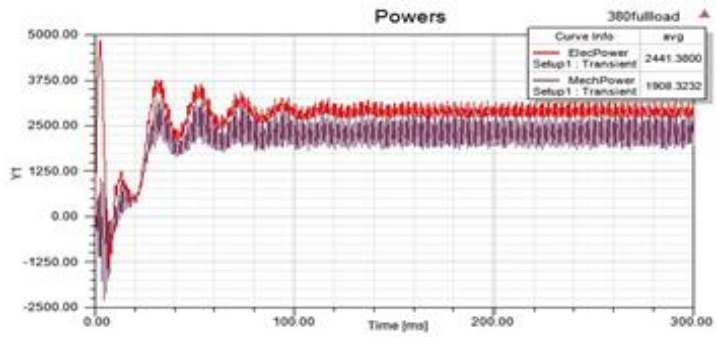

(b)

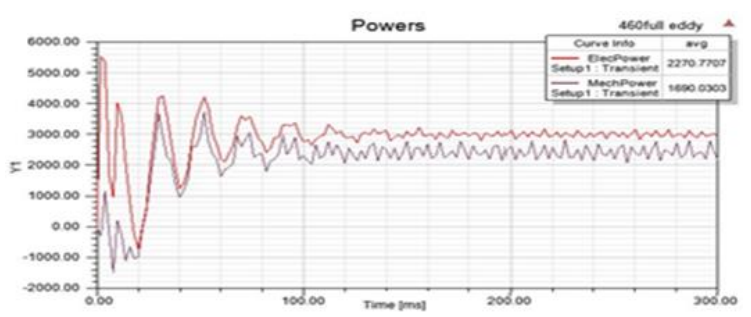

(d)

Figure 11. Effect the applied voltage on electrical and mechanical power. (a) Power at 340V (b) Power at $380 V$ (c) Power at 420V (d) Power at 460V 


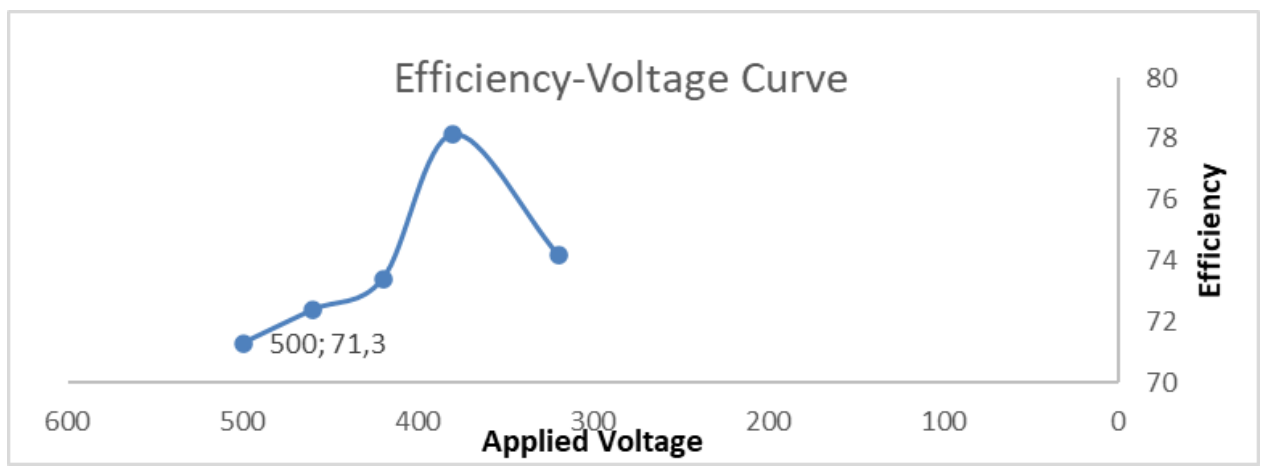

Figure 12. Efficiency voltage curve

Figure 12 clearly explains the effect of changing voltages on the motor efficiency greatly when changing voltages more than $10 \%$.

\section{CONCLUSION AND DISCUSSION}

Investigation the behavior of squirrel cage induction motor under different voltage operation conditions involves a deep knowledge about voltage variation effects on motor performances. Finite element method is a perfect tool for calculation of magnetic fields density and intensity of the model under design. The aim of this work is to study the squirrel cage induction motor performances. A static and dynamic model for the motor has been modeled and analyzed using 2-D Finite element method. This method provides an accurate representation of the geometry, materials, non-linear behavior of magnetic field distribution and give the ability to clarification the effect of apply voltage on motor current, torque, power and efficiency. The model has been used to simulate the SCIM under variable voltage values using ANSYS Maxwell 2D and Rmxpert programs. A 2-D transient analysis based on FEM is implemented to compute the effect of changing the voltage on the performance of SCIM dynamic model. The results give a real effect of voltages on motor performances and the simulated model gives corresponding with the experimental motor. As is evident from the results the motor efficiency will be decreases in both case increase or decrease the voltage that mean any value of voltage except the rated voltage who designed the efficiency will decrease, Also the motor electrical and mechanical power in addition to torque will decrease tow as result for this study the deviation on supply voltage must be in range of $\pm 10 \%$.

\section{REFERENCES}

[1] Szabó L., Tóth F., Kovács E., Fekete G., "An overview on induction machine's diagnosis methods0," Journal of Computer Science and Control Systems, Oradea, pp. 229-234. 2008.

[2] García-Gracia, M., Jiménez Romero, Á., Martín Arroyo, S. "Cogging Torque Reduction Based on a New Pre-Slot Technique for a Small Wind Generator," Energies, MDPI, Open Access Journal, vol. 11, no. 11, pp. 1-15, 2018.

[3] Isam M., Abdulrahim T., Omar K. Alazzawi, "Application of FEM to Provide the Required Database for MCSA Based On-line Fault Detection System on 3-phase Induction Motor using ANSYS Maxwell2D," Advances In Natural And Applied Sciences, vol.16, pp. 43-54, 2016

[4] Bahget, K., V., Patel H., "Electromagnetic Analysis of Induction Motor using FEM," Journal of Emerging Technologies and Innoviative Researh. (JETIR), vol. 1, no. 7, pp. 903-908, 2014.

[5] Nakasone, Y., S. Yoshimoto, T.A. Stolarski, "Engineering Analysis with ANSYS Software," Elsevier ButterworthHeinemann, Linacre House, Jordan Hill, Oxford OX2 8DP, ISBN 075066875 X, 2006.

[6] Liu, G. R., and S. S. Quik, "The Finite Element Method A Practical Course," Butterworth-Heinemann, An imprint of Elsevier Science, Linacre House, Jordan Hill, Oxford OX2 8DP, ISBN 075065866 5, 2003.

[7] M. H. Gmiden and H. Trabelsi, "Calculation of Two-Axis Induction Motor Model using Finite Elements with Coupled Circuit," 6th IEEE International Multi-Conference on Systems, Signals and Devices, pp. 1-6 2009.

[8] Bacher, J. and C. Grabner, "Implemented Finite Element Routines for the Calculation of Quasi-Steady and Transient Characteristics of a Squirrel Cage Induction Machine", in World Congress on Engineering and Computing science, WCECS, pp. 22-24, 2008.

[9] Jason R. Stack, Thomas G. Habetler, Ronald G. Harley, "Fault classification and fault signature production for rolling element bearings," IEEE Transactions on Industry Applications, vol. 40, no. 3, pp.735-739, 2004.

[10] Bensalem, Y., Abdelkrim, M. N., "Modeling and Simulation of Induction Motor Based on Finite Element Analysis," International Journal of Power Electronics and Drive System (IJPEDS). vol.7, no.4, 2016.

[11] Bacher J. and Grabner C., "Implemented Finite Element Routines for the Calculation of Quasi-Steady and Transient Characteristics of a Squirrel Cage Induction Machine," the proceedings of the World Congress on Engineering and Computing Science, WCECS, pp. 22-24, 2008. 
[12] Boglietti A., Cavagnino A., Lazzari M., "Computational Algorithms for Induction Motor Equivalent Circuit Parameter Determination-Part II: Skin Effect and Magnetizing Characteristics," IEEE Transactions on Industrial Electronics, vol. 58, no. 9, pp. 3723 - 3733, 2011.

[13] M. H Remlan, R. Aziz, S. Salimin, "Comparison of different magnet arrangement on performance of flux reversal permanent magnet (FRPM) machine," International Journal of Power Electronics and Drive System (IJPEDS), vol. 10, no. 3, pp. 1207-1214, 2019.

[14] M. Rezal, D. Ishak., "Performance evaluation of multi-phase permanent magnet synchronous motor based on different winding configurations and magnetization patterns," International Journal of Power Electronics and Drive System (IJPEDS), vol. 10, no. 3, pp. 1197-1206, 2019.

[15] Zhou Rui, Wang Qunjing, Li Guoli, Pang Cong, Fang Guanghui, "Optimal design of single-phase induction motor based on MAXWELL 2D Rmxprt," Electrical Machines and Systems (ICEMS), 2010 International Conference on, pp.1367,1370, 2010.

[16] Qiu Changli, Cheng Jihang, Li Jingquan, "Simulation analysis of the performance of linear introduction motor in Maxwell 2D," Electrical \& Electronics Engineering (EEESYM), 2012 IEEE Symposium on, pp.360- 363, 2012.

[17] Mei-shan Jin, A-lin Hou, Chang-li Qiu, Da-chuan Chen, "A Maxwell 2D emulated analysis in the performance of linear introduction motor," International Conference on Computer, Mechatronics, Control and Electronic Engineering (CMCE), vol. 4, pp. 348-351, 2010.

[18] Zhou Rui, Wang Qunjing, Li Gouli, Pang Cong, Fang Guanghui, "Optimal Design of single-phase induction motorbased on MAXWELL 2D Rmxprt," IEEE International Conference of Electrical Machines and Systems, (ICEMS), pp. 1367-1370, 2010.

[19] Mohammad Jahirul Islam, "Finite-Element Analysis of Eddy Currents In The Form-Wound Multi-Conductor Windings Of Electrical Machines," Doctoral Dissertation, Helsinki University of Technology, 2011.

[20] Aroui T., Koubaa Y. and Toumi A., "Magnetic Coupled Circuits Modeling of Induction Machines Oriented to Diagnostics," Leonardo Journal of Sciences, vol. 7, no. 13, pp. 103-121, 2008.

[21] Bossio G., De Angelo C., Jorge Solsona J., "A 2-D Model of the Induction Machine: An Extension of the Modified Winding Function Approach," IEEE Transactions on Energy Conversion, vol. 19, no. 1. pp. 144-150. 2004.

[22] Su H., Chong KT., Kumar RR, "Vibration Signal Analysis for Electrical Fault Detection of Induction Machine Using Neural Networks," Neural Comput Appl, Springer, vol. 20, no. 2, pp. 183-194, 2011.

[23] Tavner PJ., Penman J., "Condition Monitoring of Rotating Electrical Machines," Published by The Institution of Engineering and Technology, London, United Kingdom, The Institution of Engineering and Technology, 2008.

[24] Omar K. Alazzawi, Isam M. Abdulbaqi, Abdulrahim Thiab Humod, "Design and Implementation of an On-line Monitoring System of IM Based on MCSA and Vibrations (Bearings and Eccentricity Faults)," Journal of Applied Sciences Research, vol. 12, no. 11, pp. 18-30, 2016.

[25] Isam M. Abdulbaqi, AbdulrahimThiabHumod, Omar K. Alazzawi, "Design and Implementation of an On-line Diagnosis System of IM Electrical FaultsUsing MCSA and ANN Based on Labview" Australian Journal of Basic and Applied Sciences, vol. 10, no. 16, pp. 223-240, 2016. 